\title{
The Impact of Diet Counselling on Type 2 Diabetes Mellitus: An Indian Case Study
}

Dharini Krishnan ${ }^{1}$, Raj Gururajan ${ }^{2 *}$, Abdul Hafez-Baig' ${ }^{2}$, Srinivas Kondalasamy-Chennakesavan ${ }^{3}$, Nilmini Wickramasinghe ${ }^{4}$ and Rashmi Gururajan $^{5}$

${ }^{1} D$ V Living Science Pvt Ltd, India

${ }^{2}$ University of Southern Queensland, Australia

${ }^{3}$ University of Queensland, Australia

${ }^{4}$ Epworth Health Care \& Deakin University, Australia

${ }^{5}$ Monash University, Australia

\begin{abstract}
Objective: The main objective of this paper is to investigate the impact of diet counselling on patients with Type 2 Diabetes Mellitus (T2DM). Despite a number of approaches to T2DM management being already available, healthcare professionals in India still struggle to achieve health targets without the adjunct therapy of diet coaching or counselling.

Research design and methods: The study assessed the impact of counselling using a pre and post-test experimental design on separate case and control groups. The design of the study included the assessment of 150 adult subjects with T2DM and the effect of periodic intensive diet and exercise counselling on anthropometric measurements, plasma glucose, $\mathrm{HbA} 1 \mathrm{c}$, serum lipid profile and blood pressure levels. The subjects were grouped into three cohorts; those who were willing to attend only one session on diet and exercise counselling (Group I), those who were willing to attend only dietary counselling with periodic follow-up (Group II), and those who were willing to attend both dietary and exercise counselling with periodic follow-up (Group III).

Results: The results of the investigation showed that Group III participants were generally likely to follow dietary principles more carefully, and were more involved with their interactions with the counsellor. Results also indicated that subjects who received periodic, intensive diet counselling did not show symptoms of progression to diabetic complications, and also did not progress to insulin therapy for the management of their disease.. A six-month counselling program clearly indicated that this intervention had a positive effect on the management of non-insulin dependant T2DM.
\end{abstract}

Keywords: Type 2 Diabetes; Counselling; India; Hyperglycaemia; Insulin secretion; Insulin therapy

\section{Introduction}

Diabetes refers to any of the diseases characterized by an excessive discharge of urine. The word 'diabetes' literally translates as 'siphon', or 'pass through' [1]. Diabetes Mellitus is a chronic hereditary disease characterised by a lack of endogenous insulin and resulting in hyperglycaemia and the excretion of excess glucose in urine. The basic defect appears to be an absolute or relative lack of insulin production from the pancreas, which leads to abnormalities mainly in carbohydrate metabolism, as well as in protein and fat metabolisms. Severe untreated diabetes, of which hyperglycaemia is just one aspect of metabolic derangement, can lead to both macro and microvascular complications. A relatively simple and non-invasive method of preventing these complications is to recognise the impact of diet on insulin production and maintenance. Therefore, people with diabetes mellitus need help in planning and accepting a daily diet which contains the appropriate amounts of carbohydrates, protein, fat and fibre, together with adequate amounts of vitamins and minerals [2]. It is important to distinguish that Type I Diabetes Mellitus (T1DM) is characterised as an autoimmune disease, while Type II Diabetes Mellitus is an acquired chronic disease characterised by decreased insulin secretion and an increase in insulin resistance. Although diet plays a role in T1DM, it has a greater impact in the management of T2DM.

Epidemiological studies globally suggest that the incidence of diabetes is increasing, particularly in areas where there has been significant economic improvement due to industrialisation and more generous food supply. Advancing age, obesity, higher economic status, sedentary habits and a family history of diabetes are the most common predisposing factors.

Asians from the Indian subcontinent are known to have a higher prevalence of T2DM than host populations and other migrant ethnic groups. Studies conducted in several Asian countries in the last decade highlighted a rising prevalence of T2DM in the urban population [3].

The prevalence of T2DM in India was reported by Ramachandran (2002) to be 2.4 percent in rural populations and 11.6 percent in urban populations. Demographic transition due to improved living conditions in rural India was associated with a three-fold increase in the prevalence of diabetes [3]. The most disturbing trend, however, is the significant shift in age of onset of T2DM, towards a younger

*Corresponding author: Professor Raj Gururajan, $\mathrm{PhD}$, Professor of Information Systems, School of Management \& Enterprise, University of Southern Queensland, Sinnathamby Boulevard, Springfield Central QLD 4300, Australia, Tel: +61 73470 4539; E-mail: gururaja@usq.edu.au

Received August 24, 2015; Accepted September 25, 2015; Published September 29, 2015

Citation: Krishnan D, Gururajan R, Baig AH, Chennakesavan SK, Wickramasinghe $\mathrm{N}$, et al. (2015) The Impact of Diet Counselling on Type 2 Diabetes Mellitus: An Indian Case Study. J Diabetes Metab 6: 610. doi:10.4172/2155-6156.1000610

Copyright: (c 2015 Krishnan D, et al. This is an open-access article distributed under the terms of the Creative Commons Attribution License, which permits unrestricted use, distribution, and reproduction in any medium, provided the original author and source are credited. 
population. This could have long-lasting adverse effects on the nation's overall health and economy, particularly contributing to an increase in the burden of health [4]. Despite using different methodologies, which at times show large differences in country-specific estimates, these reports have arrived at remarkably similar global figures for the incidence and prevalence of diabetes.

Impaired glucose tolerance (IGT) and impaired fasting glucose (IFG), are pre-diabetes diagnoses that signify different abnormalities of glucose control. If not addressed appropriately and effectively, a diagnosis of IGT or IFG will often lead to T2DM. In addition to diabetes, the condition of IGT also constitutes a major public health problem, both because of its association with diabetes incidence and its association with increased risk of cardiovascular disease.

The International Diabetes Federation predicts that India will reach a prevalence of about 73.5 million people with diabetes mellitus in the year 2025, and that it will emerge as the global capital for diabetes. Country-wise population prevalence of diabetes and an expected increase in number showed that India is likely to be followed by China and the U.S. [5]. Wild [6] opined that given the increasing prevalence of metabolic syndrome, it is likely that these figures provide an underestimate of future diabetes prevalence.

Although vastly different in social and cultural aspects, the Northern and Southern states of India seem to possess an identical risk of developing diabetes if exposed to an urban lifestyle. Most migrant Indians living in the UK are from the North Western states, such as Gujarat and Punjab, while those in South Africa, Singapore and Fiji are from Southern Indian states. All of them have been reported to have an equal susceptibility to diabetes when exposed to urban environmental conditions, perhaps suggestive of an inherent genetic vulnerability to developing diabetes. Shah $[7,8]$ reported the phenomenon to be true within the Indian subcontinent where internal migration from rural to urban areas is taking place. A trend in the prevalence of T2DM in India is presented in the table below (Table 1).

The data above indicates a dramatic increase in the prevalence rate of diabetes mellitus amongst sub continental Indians over a span of over thirty years. The prevalence of diabetes mellitus in urban Indian adults is 12 percent, while in most European populations it is only around six percent [9].

\section{Risk factors for type 2 diabetes mellitus}

Webster [6] defined risk factors as something that increases a person's chances of developing a disease. According to Ramachandran [10] important risk factors for high prevalence of diabetes include obesity, central adiposity (increased waist to hip ratio), age, family history of diabetes and lifestyle changes due to urbanization. The ability to reverse or modify a risk factor results in two different subtypes of classification - non-modifiable and modifiable risk factors, otherwise known as host risk factors and reversible risk factors.

When considering T2DM, there are four main non-modifiable risk factors; age, gender, race and family history. These factors cannot be reversed because they are inherently linked to each person diagnosed with the disease and cannot be altered in any way.

A short discussion on these non-modifiable risk factors is presented below. Although there is no conclusive data for some of the risk factors, there is supportive evidence suggestive of a correlation between the factor and the development of T2DM.

Age: The incidence of T2DM is not limited to particular age groups, and can affect any person of any age. In Indians, T2DM is developing at a younger age compared to their European counterparts, with an increase in incidence seen in urban populations as compared to the rural population in India. Age-standardised prevalence of diabetes has increased in an urban population in India [11,12].

Gender: Many studies do not comment on differences between genders as a risk factor for T2DM $[4,13,14]$. Contrary to this, however, the prevalence of T2DM was higher in men than in women in a study conducted on Caucasians in the UK $[15,16]$. Women are generally considered at lower risk of cardiac-related morbidity and mortality than men. It is globally believed that diabetes erases this advantage in females and increases the risk of coronary heart disease to a greater extent than in men [17].

The prevalence of undiagnosed diabetes, as well as combined IFG and IGT testing did not differ by gender in an Iranian urban population; IFG was more prevalent among men than women, whereas IGT was more prevalent among women than men. The prevalence of diagnosed diabetes was higher in women than men, although it is possible that this was due to a higher catchment rate in women than in men. No significant difference was observed in the total prevalence of diabetes between men and women [18]. To date, no conclusive evidence has been provided with regards to gender difference in the prevalence of T2DM.

Race: The risk for T2DM varies among different population groups. Diabetes also seems to pose higher or lower risks for specific complications among certain ethnic groups. Genetic and socioeconomic factors, or both, seem to be involved in some ethnic differences, but in most cases the observed increase in subcontinental Indians is due to dramatic changes in traditional lifestyles over a relatively short period of time. One important factor contributing to increased T2DM in Asian Indians is excessive endogenous insulin resistance when compared to their Caucasian counterparts. This difference in the degree of insulin resistance may be explained by either an environmental or a genetic factor, or by a combination of both [19]. Globally agreed upon that Asian Indians are at a higher risk of developing T2DM due to their racial background.

\begin{tabular}{|c|c|c|c|c|c|}
\hline \multirow{2}{*}{ Year } & Source & \multirow{2}{*}{ Place } & \multirow{2}{*}{ Area } & \multicolumn{2}{|c|}{ Prevalance (\%) } \\
\cline { 5 - 6 } & & & & Urban & Rural \\
\hline 1971 & Tripathy et al. & Cutttack & (Central) & 1.2 & \\
\hline 1972 & Ahuja et al. & New Delhi & (North) & 2.3 & \\
\hline 1979 & Gupta et al. & Multicentre & & 3.0 & 1.3 \\
\hline 1979 & Johnson et al. & Madurai & (South) & 0.5 & \\
\hline 1984 & Murthy et al. & Tenali & (South) & 4.7 & \\
\hline 1986 & Patel & Bhadran & (West) & 3.8 & \\
\hline 1988 & Ramachandran et al. & Kudremukh & (South) & 5.0 & \\
\hline 1989 & Kodali et al. & Gangavathi & (South) & & 2.2 \\
\hline 1989 & Rao et al. & Eluru & (South) & & 1.6 \\
\hline 1992 & Ramachandran et al. & Madras & (South) & 8.2 & 2.4 \\
\hline 1997 & Ramachandran et al. & Madras & (South) & 11.6 & \\
\hline 2000 & Ramachandran et al. & Kerala & (South) & 12.4 & 2.5 \\
\hline 2001 & Misra et al. & New Delhi & (North) & 10.3 & \\
\hline 2002 & Mohan et al. & Chennai & (South) & 12.1 & \\
\hline 2004 & Shaukat et al. & National & & 5.6 & 2.7 \\
\hline
\end{tabular}

Note: Different Sample Selection Criteria

Source: Ramchandran et al. (2004)

Table 1: A rising trend in the prevalence of type 2 diabetes in India. 
Family history: About a third of people living with T2DM have family members with diabetes [20] and pose a forty per cent risk of developing diabetes. American Diabetes Association [20] reported that people with a family hnnnnnnnistory of diabetes ha an increased risk of developing the disease at an earlier age and with more severe features. When clusters of T2DM appear within families, genetic factors should be strongly suspected.

\section{Management of type 2 diabetes mellitus}

Early diabetes management should focus on lifestyle modification, specifically modest weight loss and increased physical activity. Even at an advanced stage of diabetes, lifestyle and diet intervention are likely to be beneficial in curbing the complications of sustained hyperglycaemia. Public health messages, health care professionals, and healthcare systems in general should advocate behaviour changes to achieve a healthy lifestyle and thereby reduce the negative impacts of T2DM. Although there is no way to modify one's genetic background, if lifestyle is given as much importance as risk factors, interventions can be developed to attenuate this risk. Lifestyle changes can be applied broadly, or can be directed to individuals who are judged to be at increased genetic risk for diabetes as ascertained by information such as family history of diabetes. de Alba Garcia [27] suggested that daily exercise with a preference for walking was the choice for the subjects with uncontrolled diabetes to avoid complications of the disease.

Historically, nutritional recommendations for diabetes and related complications were based on scientific knowledge, clinical experience, and expert consensus; however, it was often difficult to discern the level of evidence used to develop these recommendations. Emphasising this aspect, the American Diabetes Association released a position statement in 2002 to provide recommendations and principles to be followed for medical nutrition therapy. The best available evidence, however, must still take into account individual circumstances and cultural and ethnic preferences, and the person with diabetes should be involved in the decision-making process so as to ensure a better level of compliance. It is well established that self-motivated lifestyle changes are more effective than a paternalistic approach to the same. By encouraging and allowing to the patient to draw their own conclusions about adopting a healthy lifestyle, there is a higher likelihood that they will make permanent and effective changes [22,23].

According to Davidson and Passmore [21], there are three streams of lifestyle and medical interventions:

i) Diet [24].

ii) Diet and oral hypoglycemic agents [25].

iii) Diet and insulin.

\section{Diet alone}

Prolonged dietary treatment of diabetes is the very baseline of all forms of anti-diabetic treatment [26]. An important cornerstone in the management of diabetes and achievement of the aim of dietary treatment is a well designed meal, taking account of the total calorie content and nature of diet [24,27].

Diet and oral hypoglycemic agents: Diet combined with oral hypoglycaemic agents is the next tier in diabetes treatment. There are several classes of orally administered antidiabetic agents available for use in patients with T2DM, as discussed below. By taking advantage of differing mechanisms of action, combination therapy is evolving as a means of optimizing glycaemic control in patients in whom a single agent or insulin is inadequate. Combinations of orally administered agents can often delay the need for insulin or in combination with insulin aid in achieving glycaemic goals [24,28]. This method of treatment is often preferred by clinicians and patients alike, as it not only minimises the effort needed for lifestyle interventions, but also provides an instant solution to hyperglycaemia. Ideally, patients who require medical intervention should be commenced on oral treatment while also working towards the recommended lifestyle habits clinically, however, this is not often carried out.

There are various kinds of oral hypoglycaemic agents available for the treatment of diabetes mellitus:

Insulin secretagogues: These agents directly stimulate insulin secretion from the cells of the pancreas. They include the sulphonylureas and the non-sulphonylureas.

Sulphonylureas: The sulphonylureas stimulate insulin secretion in subjects who fail to comply with exercise and diet regimens or in whom the fasting blood glucose level is not adequately lowered by the initial therapeutic regimen. A significant disadvantage of suphonylureas is the tendency for individuals to gain weight as they achieve glycaemic control.

Non-sulphonylureas: Non-sulphonylureas primarily reduce postprandial hyperglycaemia and are also known as prandial insulin secretagogues. Currently, two agents are available for clinical use in India; repaglinide (benzoic acid derivative) and nateglinide (phenylalanine derivative) [29].

Insulin sensitizers: Insulin resistance, at the level of liver, adipose tissue and skeletal muscle, plays a major role in the pathophysiology of T2DM. Biguanides and thiazolidinediones are the currently used insulin sensitizers.

Biguanides: Biguanides are the preferred hypoglycemic agent for subjects with type 2 diabetes mellitus who are overweight as they do not have a side effect of weigh gain. The commonly used biguanides are Metformin and Phenformin. Biguanides have no pancreatic action, but they increase the number of insulin receptors in the body, reduce hepatic gluconeogenesis, increase peripheral uptake of glucose, and also reduce the absorption of carbohydrates to some extent.

Thiazolidinediones: Thiazolidinediones reduce insulin resistance at the level of skeletal muscle and adipose tissue. Pioglitazone and rosiglitazone are the two agents in clinical use. Agents such as biguanides and thiazolidinediones which enhance insulin sensitivity, are used to optimise the management of T2DM [30,31].

\section{Inhibitors of intestinal carbohydrate metabolism}

a -glucosidase inhibitors (AGIs): a-glucosidases are enzymes involved in the breakdown of complex carbohydrates to monosaccarides for absorption in the jejunum. They include maltase, isomaltase, dextranase, glucoamylase and sucrase expressed in the brush border of the enterocytes lining the intestinal villi. AGIs are competitive, reversible inhibitors of these enzymes that prevent breakdown of oligosaccharides and disaccharides to monosaccharides. This retards the rate of carbohydrate digestion, delaying and decreasing the rise in postprandial plasma glucose. The agents in clinical use are acarbose, miglitol and voglibose [19,30,31].

Agents targeting the entero-insular axis and the incretins: These agents are not yet available for clinical use in India. The presence of an entero-insular axis was made apparent by the fact that using equivalent 
glucose loads, oral glucose tolerance tests resulted in a higher insulin peak than the intravenous glucose tolerance test. Gut hormones contributing to incremental insulin release were called 'incretins'. GLP-1 is the major incretin and is secreted by the ileum and, to some extent the colon, with levels rising within fifteen minutes of ingesting a meal. Impaired glucose tolerance and type 2 diabetes mellitus are characterized by low levels of GLP - 1 with normal sensitivity. Clinical use of GLP-1 needs continuous infusion as it is rapidly degraded. This is overcome by using enzyme resistant analogues (Exendin 4, Liraglutide) or with DPP IV inhibitors [29,32].

Diet and insulin: When a subject with T2DM cannot be managed with diet and oral hypoglycemic agents, insulin is introduced for better management of the condition. Insulin therapy in T2DM supplements endogenous insulin and is often given as a single injection before breakfast or at bedtime. Most insulin treated obese subjects with T2DM can be managed with three meals and a bed time snack [33,34]. Many of them receive sulphonylurea therapy as well as insulin because this combination decreases the amount of insulin required. When diabetes and obesity occur together, over eating is a major contributor to the hyperglycaemia in the insulin treated individuals, so any reduction in energy intake reduces insulin requirements [35].

Treatment with insulin or insulin secretagogues requires consistency in timing of meals and carbohydrate content. Multiple insulin dosing regimens allow for a more flexible food intake and lifestyle in persons with T2DM [36].

Management of diabetes mellitus entails the management of blood parameters, exercise and stress. Persons with T2DM have to maintain their blood values within the following limits prescribed for glycosylated haemoglobin (HbA1c), fasting and postprandial glucose values.

According to Kalra and Brink [31,37] education, exercise, diet, oral medications and insulin are the treatment for diabetes. According to an Indian Council for Medical Research (ICMR) survey, the prevailing treatment modalities for T2DM in India are, diet alone (11 per cent); oral hypoglycemic agents (OHA) (62 per cent); insulin (4.5 per cent); insulin plus OHA (8.5 per cent) and other methods (14 per cent) [38].

Albright and Saleh [39,40] suggested that nutrition recommendations for a healthy lifestyle for the general public were also appropriate for persons with type 2 diabetes mellitus. Many persons with T2DM are overweight, insulin resistant and also have dyslipidaemia and hypertension [41-49]. Therefore, medical nutrition therapy for T2DM should emphasize lifestyle strategies, to reduce hyperglycemia, dyslipidemia, and blood pressure [50] that result in reduced energy intake and increased energy expenditure through physical activity.

Increased physical activity is effective in preventing type 2 diabetes mellitus, and the protective effect is especially pronounced in persons at the highest risk for the disease [51]. A minimum expenditure of $1,000 \mathrm{kcal} /$ week from physical activities is recommended by [52]. It is clear from prospective cohort studies that exercise of moderate or vigorous intensity performed on a regular basis has an important role in the primary prevention and treatment of type 2 diabetes [53-55]. People with type 2 diabetes mellitus are prescribed moderate exercise at regular intervals to help manage the disease.

In general one can cope with stress by focusing either on the emotional effects of stress or solving the problems of stress, or both [56]. Management of type 2 diabetes for stress could be through breathing techniques or listening to soft classical music. A lot of research is being carried out in relation to stress and management of diabetes [57].

Thus management of type 2 diabetes is very complex and needs a team of people to help manage the disease. The most important factors are blood parameters, diet, exercise and stress.

\section{Research objectives}

The present study was designed to determine the effect of periodical intensive counselling, on diet and on diet and exercise for a period of six months, on the anthropometric measurements, plasma glucose measurements and $\mathrm{HbAlc}$, serum lipid parameters and blood pressure levels of subjects with type 2 diabetes mellitus.

\section{Research design of the study}

One hundred and fifty subjects of both genders in the age group of 40 to 60 years, were selected for the study. These subjects were registered as outpatients in the Dr. V. Seshiah Diabetes Care and Research Institute, Chennai, a private referral center in Tamil Nadu State, South India. Based on their willingness, they were assigned to one of the three groups each comprising of fifty subjects. Group I received counselling on diet and exercise only once, Group II subjects were given periodic intensive counselling on diet only, and Group III on both diet and exercise.

Information regarding the age, socio-economic status, occupation, personal habits like smoking, alcohol consumption and physical activity and the family history of diabetes of the subjects were collected using an interview schedule. Dietary pattern and dietary intake of the subjects were also assessed. Data was subjected to descriptive analysis. The anthropometric measurements, plasma glucose levels, HbAlc lipid parameters and blood pressure levels of all the subjects were assessed at different periods and subjected to statistical analysis.

This study was an experimental study with a pre-test, post-test design with a control group. The study was designed to assess the effect of periodic intensive counselling on diet, and periodic intensive counselling on diet and exercise on the anthropometric measurements, plasma glucose, HbA1c, serum lipid profile and blood pressure levels of adult subjects with type 2 diabetes mellitus.

Selection of the sample: One hundred and fifty adult subjects with type 2 diabetes mellitus who fulfilled the inclusion criteria were selected for the study. These subjects were from Dr. V. Seshiah Diabetes mellitus Care and Research Institute, Chennai, a private referral center of Tamil Nadu. Fifty subjects were assigned to one of the following three groups

Group I: Subjects who were willing to attend only one counselling session on diet and exercise.

Group II: Subjects who were willing to attend counselling only on diet with periodic follow-up.

Group III: Subjects who were willing to attend counselling for both diet and exercise with periodic follow- up.

Criteria for selection of the subjects: The subjects were selected for the study according to the following inclusion and exclusion criteria.

\section{Inclusion criteria}

- Adults with type 2 diabetes mellitus diagnosed within the last one and a half years and on oral hypoglycemic drugs. 
- Subjects in the age group of 40 to 60 years belonging to both sexes.

- Willingness of the subjects to participate in the study

\section{Exclusion criteria}

- Subjects who are on insulin for management of diabetes mellitus.

- Subjects who are suffering from any other major health complications.

- Subjects pregnant at the time of the study.

Ethics Committee approval: Institutional ethics committee of the Women's Christian College, Chennai approved this proposed study. Written informed consent was obtained from each one of the subjects who participated in this study.

\section{Tools used for data collection}

1. Interview schedule: An interview schedule was prepared to elicit information from the subjects regarding age, family history of diabetes, occupation, socio-economic status, personal habits like alcohol consumption and smoking, physical activity as well as information about their dietary pattern. Each subject was interviewed individually by the investigator and the response was immediately recorded on the schedule.

\section{Anthropometric measurements:}

Height: of the subjects was recorded using a stadiometer. The subjects were requested to remove their foot wear and stand with heel and head against the stadiometer and the heights were recorded to the nearest $0.1 \mathrm{~cm}$.

Body weight : of the subjects was measured using an Avery Weighing Scale. The subjects were requested to stand on the instrument without their footwear and weights were recorded to the nearest $0.5 \mathrm{~kg}$.

Body Mass Index (Quetelet's Index): was calculated as weight in kilograms divided by height in meters squared. The Body Mass Index (BMI) of the subjects was calculated using the following formula.

$$
\mathrm{BMI}=\frac{\operatorname{Body} \operatorname{Weight}(\mathrm{Kg})}{\operatorname{Height}\left(\mathrm{m}^{2}\right)}
$$

\section{Biochemical indices}

The biochemical estimations were carried out in Dr.V.Seshiah Diabetes Care and Research Institute, Chennai. The blood samples drawn from the subjects were analysed for the following parameters:

a. Estimation of plasma glucose by the enzymatic kit method Roche Glucose GOD-PAP.

b. Estimation of Glycosylated Hemoglobin by the enzymatic kit method - BIO- RAD Ref: 220 - 0101.

c. Estimation of serum total cholesterol by the enzymatic kit method - Roche Cholesterol CHOD-PAP

d. Estimation of Serum HDL-C plus by the enzymatic kit method - Roche.

e. Estimation of serum triglycerides by the enzymatic kit method Roche Triglycerides GPO- PAP.

The following parameters were calculated

1. Serum LDL cholesterol was calculated using the formula of [58]

\section{Serum VLDL cholesterol}

3. Serum total cholesterol : HDL cholesterol ratio

4. Serum triglycerides : HDL cholesterol ratio

\section{Blood pressure measurement}

The blood pressure levels of the subjects were recorded by the doctors using a manual sphygmomanometer. The blood pressure was recorded on the 1st, 90th and 180th day of the study period.

\section{Results and Discussion}

The data regarding the age, gender, socio-economic status, occupation, personal habits namely, alcohol consumption and smoking, physical activity, family history of diabetes and dietary pattern of the subjects were collected using an interview schedule.

\section{Gender and age distribution}

Distribution of subjects according to gender and the mean age is presented in the table below (Table 2).

Results showed that the mean age range of the subjects was 50.4 to 51.9 years. The mean age of the subjects in Group I ( $51.9 \pm 5.3$ yrs.) was slightly higher than that found in Groups II and III. Whereas the mean age of the subjects in Group II was almost equal to that of Group III subjects.

\section{Income of the subjects}

The income of the subjects was categorized as very low income, low income, middle income and high income as per the classification given by the Housing and Urban Development Corporation (HUDCO). Income classification by HUDCO is shown in the table below (Table 3 ).

The percentage distribution of subjects on the basis of their monthly family income is shown in the table below (Table 4).

From the above table, it can be deduced that majority of the subjects in all the three groups belonged to the high income category. A small percentage of the subjects in Group I (26.7\%), Group II (11.6\%) and Group III (4.3\%) belonged to the middle income category. Only a small percentage of subjects in Group III (2.2\%) and Group I (4.4 \%) belonged to the low income category.

\section{Personal habits of the subjects}

The percentage distribution of subjects based on their personal

\begin{tabular}{|c|c|c|c|c|c|c|c|}
\hline \multirow{3}{*}{ Group } & \multirow{3}{*}{$\begin{array}{l}\text { Number of } \\
\text { subjects }\end{array}$} & \multicolumn{4}{|c|}{ Gender } & \multirow{3}{*}{$\begin{array}{l}\text { Age range } \\
\text { (years) }\end{array}$} & \multirow{3}{*}{$\begin{array}{l}\text { Mean age } \\
\pm \text { SD }\end{array}$} \\
\hline & & \multicolumn{2}{|c|}{ Male } & \multicolumn{2}{|c|}{ Female } & & \\
\hline & & No. & $\%$ & No. & $\%$ & & \\
\hline Group I & 45 & 20 & 44.4 & 25 & 55.6 & 50 to 60 & $51.9 \pm 5.3$ \\
\hline Group II & 43 & 15 & 34.9 & 28 & 65.1 & 50 to 60 & $50.4 \pm 5.9$ \\
\hline Group III & 46 & 31 & 67.4 & 15 & 32.6 & 50 to 60 & $50.5 \pm 6.3$ \\
\hline
\end{tabular}

Table 2: Gender, age range and mean age of the subjects.

\begin{tabular}{|c|c|}
\hline Income Group & Monthly income in rupees \\
\hline Very Low Income & Less than 2101 \\
\hline Low Income & 2101 to 4500 \\
\hline Middle Income & 4501 to 7500 \\
\hline High Income & Above 7500 \\
\hline Source: HUDCO, 2003 & \\
\hline
\end{tabular}

Table 3: Income classification by HUDCO, 2003. 


\begin{tabular}{|c|c|c|c|c|c|c|}
\multirow{2}{*}{ Group } & \multicolumn{2}{|c|}{ Low income } & \multicolumn{2}{c|}{ Middle income } & \multicolumn{2}{c|}{ High income } \\
\cline { 2 - 7 } & Number & Per cent & Number & Per cent & Number & Per cent \\
\hline Group I & 2 & 4.4 & 12 & 26.7 & 31 & 68.9 \\
\hline Group II & 0 & 0 & 5 & 11.6 & 38 & 88.4 \\
\hline Group III & 1 & 2.2 & 2 & 4.3 & 43 & 93.5 \\
\hline
\end{tabular}

Table 4: Percentage distribution of subjects on the basis of monthly family income.

\begin{tabular}{|c|c|c|c|c|c|c|c|c|}
\hline \multirow{2}{*}{ Group } & \multicolumn{3}{|c|}{ Cigarette smoking } & \multicolumn{4}{c|}{ Alcohol consumption } \\
\cline { 2 - 9 } & \multicolumn{2}{|c|}{ Yes } & \multicolumn{2}{c|}{ No } & \multicolumn{3}{c|}{ Yes } & \multicolumn{2}{c|}{ No } \\
\cline { 2 - 9 } & No. & $\%$ & No. & $\%$ & No. & $\%$ & No. & $\%$ \\
\hline Group I & 3 & 6.7 & 42 & 93.3 & 3 & 6.7 & 42 & 93.3 \\
\hline Group II & 4 & 9.3 & 39 & 90.7 & 4 & 9.3 & 39 & 90.7 \\
\hline Group III & 5 & 10.9 & 41 & 89.1 & 9 & 19.6 & 37 & 80.4 \\
\hline
\end{tabular}

Table 5: Percentage distribution of subjects based on their personal habits.

habits like cigarette smoking and alcohol consumption is given in the table below (Table 5).

From the above table, it can be inferred that 10.9 per cent of the subjects in Group III were smoking cigarettes as against 9.3 per cent in Group II and 6.7 per cent in Group I. Will [58] reported a dosedependent association between cigarette smoking and diabetes mellitus, as well as evidence that removal of the exposure diminishes the risk of developing diabetes. Smokers with diabetes are more likely to get nerve damage and kidney disease [59] and to have higher HbAlc levels [60]. Smoking cessation programmes should target subjects with type 2 diabetes mellitus to more effectively prevent complications and promote successful management of diabetes [61].

In Group III, 19.6 per cent of the subjects consumed alcohol regularly whereas in Groups II and I it was found to be 9.3 per cent and 6.7 per cent respectively. Alcohol intake appears to be associated with risk of type 2 diabetes especially in men [62]. Another study reported that among men with a $\mathrm{BMI}=22.1 \mathrm{~kg} / \mathrm{m}^{2}$, moderate alcohol consumption was associated with a reduced risk of type 2 diabetes mellitus, but among lean men with $\mathrm{BMI}=22.0 \mathrm{~kg} / \mathrm{m}^{2}$, heavy alcohol consumption was associated with an increased risk of type 2 diabetes [63]. Moderate alcohol consumption may reduce the risk of type 2 diabetes mellitus; on the other hand, binge drinking and high alcohol consumption may increase the risk of type 2 diabetes mellitus in women [64].

\section{Family history of the subjects with type 2 diabetes}

The percentage distribution of subjects based on their family history of diabetes is presented in the table below (Table 6).

Seventy six per cent in Group III, 72 per cent in Group II and 57.8 per cent in Group I had their first relatives as diabetics. Only 9.3 per cent of the subjects in Group II had second relatives who were diabetics. Having a first relative as a diabetic is one of the major non modifiable risk factors $[65,66]$ and genetic factors could be playing a role in developing diabetes [20]. The above results indicated that the majority of the subjects had their first relatives as diabetics.

\section{Patient compliance to treatment}

We noticed a high level of involvement in the counselling, and as a result a high level of compliance from patients to the treatment options provided. We noticed that group I patients improving in their anthropometric measurements gradually from day 1 to 180 , and their level of $\mathrm{HbAlc}$ also reducing as they progressed to 180 days of treatment and counselling. In this group, diastolic blood pressure did not show any significant improvement. In terms of Group $\mathrm{II}<$ there was a significant reduction in their HbAlc level at the 90 and 180 day measurement. However, the postprandial levels for this group did not show any significant decrease. In Group III, we observed significant decrease in both body weight and BMI levels at the end of 90 day period. For this group, we noticed a significant decrease in the fasting plasma glucose level at the 90 and 180 day periods. Further, this level also showed significant levels of decrease in the cholesterol levels.

\section{Patient compliance to counselling}

The participation of the subjects in diet counselling was found to be very satisfying. Counselling was provided for the subjects and their caregiver/family during their visits to the referral centre. Home visits, with prior appointment were organized to provide diet counselling to subjects who could not attend counselling sessions due to some valid reasons. Spouses of most of the subjects were actively involved in the counselling sessions, with some even seeking counselling over the telephone for the sessions missed.

Feedback from subjects indicated that adherence to the diet prescribed was most difficult during festivals and special occasions. During festival days, preparation and consumption of sweets and fried snacks are an essential part of the traditional celebrations. Subjects were encouraged to enjoy the celebrations with low fat snacks and sweets prepared with artificial sweeteners.

This study found that the average consumption of vegetables for a family of four members was only about 100 gms. Subjects preferred consuming raw vegetables with yoghurt rather than eating them as a plain salad. Subjects also had a lot of taboos regarding fruits and vegetables consumption. Gourd vegetables and citrus fruits were avoided during rainy season as they were believed to be cold producing foods. Many of the subjects did not consume any fruit as they believed fruits were not permitted for subjects with diabetes.

The consumption of vegetables was further reduced in the diet of non- vegetarians as vegetable dishes were not usually included in nonvegetarian meals. Further the average quantity of non- vegetarian food procured was more than the quantity of vegetables usually procured. Vegetarian dishes were usually consumed for one meal, whereas nonvegetarian dishes, if prepared were carried over for two to three meals.

The biggest challenge in diet counselling therefore was to encourage increased intake of vegetables and to clear misconceptions about the inclusion of fruit in the diet of subjects with type 2 diabetes mellitus. Subjects were encouraged to increase their vegetable intake and include green leafy vegetables regularly in their diets. They were also advised to include fruits in prescribed amounts in their daily diet. Non-vegetarians were encouraged to include vegetable dishes along with the non- vegetarian dishes.

All the subjects selected for the study were on oral hypoglycemic drugs (either insluin secretogogues or insulin sensitizers or a

\begin{tabular}{|c|c|c|c|c|c|c|}
\hline \multirow{2}{*}{ Group } & \multicolumn{2}{|c|}{ First relative } & \multicolumn{2}{|c|}{ Second relative } & \multicolumn{2}{c|}{ None } \\
\cline { 2 - 7 } & No. & $\%$ & No. & $\%$ & No. & $\%$ \\
\hline Group I & 26 & 57.8 & 0 & 0 & 19 & 42.2 \\
\hline Group II & 31 & 72.1 & 4 & 9.3 & 8 & 18.6 \\
\hline Group III & 35 & 76.1 & 0 & 0 & 11 & 23.9 \\
\hline
\end{tabular}

Table 6: Percentage distribution of subjects based on their family history of type 2 diabetes mellitus. 
combination of both). Sulphonyureas and metformin were the hypoglycemic drugs commonly used. Multivitamin tablets, Vitamin $\mathrm{B}_{12}$ or Vitamin $\mathrm{E}$ were the supplements commonly consumed by the subjects as per their requirements.

This study found that subjects of Group III who received periodic, intensive counselling on diet and exercise, followed the dietary principles more carefully than subjects of Group II who received periodic intensive counselling on diet alone. Subjects of Group III were also more enthusiastic and involved in the counselling sessions, even telephoning the counsellor, between sessions for clarifications.

Subjective evaluation of the symptoms of type 2 diabetes mellitus indicated that only a small percentage of the subjects experienced symptoms like giddiness, tiredness and weakness; which are indicative of uncontrolled diabetes mellitus; during the period of the study. The biochemical profile of the subjects was monitored using tests for kidney function (microalbuminuria and serum hemoglobin) and SGOT and SGPT for liver function. Foot sensitivity and eye tests were also done at regular intervals to check for microvascular complications.

Results indicated that subjects receiving periodic intensive diet counselling did not show any symptoms of progression to diabetic complications. None of the subjects followed up during the study had progressed to taking insulin to manage their condition.

\section{Summary of Findings}

Sedentary life style, which increases the risk of type 2 diabetes mellitus, was reported by 97.8 per cent of the subjects in Group I, 97.7 per cent of the subjects in Group II and 91.3 per cent of the subjects in Group III. Majority of the subjects in Group I (95.6\%), Group II (100\%) and Group III (97.8 \%) belonged to the high income group. Majority of the subjects were non-smokers, but a small percentage of the subjects in Group I (6.7\%), Group II (9.3\%) and Group III (10.9\%) were smokers. Majority of the subjects did not consume alcohol, but a small percentage of the subjects in Group I (6.7\%), Group II (9.3\%) and Group III (19.6\%) consumed alcohol at least once a week. A large proportion of the subjects did not have any of the classic symptoms of type 2 diabetes mellitus. Subjects of Group I (6.7\%), Group II (4.7 \%) and in Group III (6.5\%) showed symptoms of polyphagia. Giddiness was experienced by subjects in Group I (8.9\%), Group II (11.6\%) and Group III (13\%). Tiredness was experienced by subjects in Group I (9.7\%), Group II (14.0\%) and Group III (10.9\%). Majority of the subjects had close relatives who were diabetics, in Group I (57.8\%), Group II (72.1\%) and Group III (76.1\%).

Among the cereals, rice was consumed more often by all the subjects as compared to other cereals like ragi, rava and wheat, which were consumed less frequently at the beginning of the study. The subjects in all the three groups consumed pulses like Bengal gram, red gram and green gram dhals frequently. Flesh foods such as egg, fish and chicken were commonly consumed by the subjects in all the three groups. Milk and buttermilk were frequently consumed by the subjects in all the three groups. Apple was the most commonly consumed fruit followed by guava and papaya, as compared to the other fruits in all the three groups. Green leafy vegetables which are rich sources of B-carotene, Vitamin C and fibre were consumed in higher amounts by all the subjects and more frequently by the subjects in Groups II and III.

Among nuts, groundnut was frequently consumed in moderate amounts by all the subjects. Sunflower oil was used by all the subjects. The next commonly used oil was gingelly oil. The mean values of the

anthropometric measurements, plasma glucose, $\mathrm{HbAlc}$, serum lipid parameters and blood pressure levels of the subjects in Group I at different periods of evaluation are given in Table 7 below.

There was a non-significant increase in mean body weight of the subjects in Group I at the end of 90 days and a significant $(p<0.05)$ decrease at the end of 180 days. A non-significant increase in BMI values was noticed at the end of 90 days and then a significant decrease at the end of 180 days. Fasting and postprandial plasma glucose showed a non-significant increase at the end of 90 days and a non-significant decrease at the end of 180 days. There was a decrease in the HbAlc values at the end of the study but it was not statistically significant There was a decrease in serum total cholesterol, LDL and triglyceride levels at the end of the study. HDL levels remained the same and VLDL showed an increase. A decrease was noticed in TC:HDL and TG:HDL ratios. All these changes were not statistically significant. Systolic blood pressure levels showed a statistically significant decrease at the end of 90 days and a non-significant decrease at the end of 180 days. Diastolic blood pressure levels showed a non-significant increase at the end of 90 days and a non-significant decrease at the end of 180 days.

The mean values of the anthropometric measurements, plasma glucose, $\mathrm{HbA1c}$ levels, serum lipid parameters and blood pressure levels of the subjects in Group II at different periods of evaluation are given in Table 8 below.

There was a statistically significant $(\mathrm{p}<0.05)$ decrease in the body weight at the end of 90 days and a non-significant decrease at the end of 180 days in subjects of Group II. There was a statistically significant reduction noted in BMI values at the end of 90 days and a non-significant decrease at the end of 180 days. Fasting plasma glucose levels showed a statistically significant $(\mathrm{p}<0.05)$ decrease at 90 and 180 days as compared to the beginning of the study. The postprandial glucose levels showed a non-significant decrease at the end of 90 days and at the end of 180 days. There was a non-significant increase in the mean $\mathrm{HbA1c}$ values of the subjects in Group II at 180 days.

There was a statistically significant $(\mathrm{p}<0.05)$ reduction in serum total cholesterol and serum LDL cholesterol levels at the end of the

\begin{tabular}{|l|c|c|c|}
\hline $\begin{array}{l}\text { Parameter } \\
\text { Anthropometric measurements }\end{array}$ & Day 1 & Day 90 & Day 180 \\
\hline Body weight $(\mathrm{kg})$ & $69.3 \pm 11.1$ & $69.6 \pm 10.9$ & $68.7 \pm 10.9$ \\
\hline BMI $\left(\mathrm{kg} / \mathrm{m}^{2}\right)$ & $27.8 \pm 4.0$ & $27.9 \pm 3.9$ & $27.5 \pm 3.9$ \\
\hline Plasma glucose values (mg/dL) & & & \\
\hline Fasting & $136.3 \pm 32.6$ & $140.2 \pm 46.3$ & $130.0 \pm 34.4$ \\
\hline Postprandial & $178.3 \pm 53.5$ & $182.8 \pm 61.8$ & $168.1 \pm 51.6$ \\
\hline HbA1c & $7.08 \pm 0.9$ & - & $7.06 \pm 1.1$ \\
\hline Serum lipid parameters & & & \\
\hline Total cholesterol (mg/dL) & $177.9 \pm 31.4$ & - & $173.0 \pm 38.8$ \\
\hline LDL-C (mg/dL) & $105.5 \pm 25.6$ & - & $98.3 \pm 26.3$ \\
\hline HDL-C (mg/dL) & $40.6 \pm 7.8$ & - & $40.6 \pm 7.1$ \\
\hline VLDL-C (mg/dL) & $30.4 \pm 12.5$ & - & $31.0 \pm 10.5$ \\
\hline Triglyceride (mg/dL) & $176.4 \pm 94.7$ & - & $175.0 \pm 81.8$ \\
\hline TC:HDL ratio & $4.4 \pm 0.8$ & - & $4.3 \pm 0.9$ \\
\hline TG:HDL ratio & $4.6 \pm 2.9$ & - & $4.5 \pm 2.3$ \\
\hline Blood pressure & & & \\
\hline Systolic blood pressure & & & \\
\hline (mm Hg) & $131.1 \pm 6.8$ & $127.3 \pm 8.4$ & $128.9 \pm 7.5$ \\
\hline Diastolic blood pressure & & & \\
\hline (mm Hg) & $80.7 \pm 3.9$ & $82.0 \pm 5.0$ & $80.2 \pm 2.6$ \\
\hline \multicolumn{2}{|c|}{ Table 7: Group I at different periods of evaluation. } \\
\hline
\end{tabular}




\begin{tabular}{|l|c|c|c|}
\hline $\begin{array}{l}\text { Parameter } \\
\text { Anthropometric measurements }\end{array}$ & Day 1 & Day 90 & Day 180 \\
\hline Body weight $(\mathrm{kg})$ & $72.3 \pm 11.9$ & $71.7 \pm 11.6$ & $72.2 \pm 11.1$ \\
\hline BMI $\left(\mathrm{kg} / \mathrm{m}^{2}\right.$ ) & $28.5 \pm 4.8$ & $28.3 \pm 4.7$ & $28.4 \pm 4.4$ \\
\hline $\begin{array}{l}\text { Plasma glucose values } \\
\text { (mg/dL) }\end{array}$ & & & \\
\hline Fasting & $154.3 \pm 59.1$ & $130.1 \pm 33.0$ & $133.3 \pm 32.7$ \\
\hline Postprandial & $194.4 \pm 69.5$ & $183.5 \pm 53.5$ & $185.5 \pm 47.3$ \\
\hline HbA1c & $7.12 \pm 1.4$ & - & $7.36 \pm 1.4$ \\
\hline Serum lipid parameters & & & \\
\hline Total cholesterol (mg/dL) & $175.3 \pm 28.8$ & - & $161.1 \pm 36.8$ \\
\hline LDL-C ( mg/dL) & $102.9 \pm 27.4$ & - & $91.08 \pm 30.6$ \\
\hline HDL-C (mg/dL) & $41.4 \pm 8.6$ & - & $39.5 \pm 9.1$ \\
\hline VLDL- C (mg/dL) & $30.3 \pm 11.0$ & - & $30.1 \pm 11.4$ \\
\hline Triglyceride (mg/dL) & $165.5 \pm 72.7$ & - & $183.3 \pm 139.9$ \\
\hline TC:HDL ratio & $4.3 \pm 0.9$ & - & $4.1 \pm 0.9$ \\
\hline TG:HDL ratio & $4.2 \pm 2.2$ & - & $4.85 \pm 3.8$ \\
\hline Blood pressure & & & \\
\hline Systolic blood pressure & & & \\
\hline (mm Hg) & $128.1 \pm 5.5$ & $129.1 \pm 10.9$ & $127.7 \pm 8.7$ \\
\hline Diastolic blood pressure & & & \\
\hline (mm Hg) & $81.2 \pm 4.5$ & $81.9 \pm 4.5$ & $80.0 \pm 3.1$ \\
\hline & & & \\
\hline
\end{tabular}

Table 8: Group II at different periods of evaluation.

\begin{tabular}{|l|c|c|c|}
\hline $\begin{array}{l}\text { Parameter } \\
\text { Anthropometric measurement }\end{array}$ & Day 1 & Day 90 & Day 180 \\
\hline Body Weight $(\mathrm{kg})$ & $73.2 \pm 12.31$ & $72.4 \pm 11.89$ & $72.5 \pm 11.91$ \\
\hline BMI $\left(\mathrm{kg} / \mathrm{m}^{2}\right)$ & $27.96 \pm 3.94$ & $27.67 \pm 3.79$ & $27.71 \pm 3.70$ \\
\hline Plasma glucose values $(\mathrm{mg} / \mathrm{dL})$ & & & \\
\hline Fasting & $141.6 \pm 53.7$ & $128.0 \pm 49.1$ & $125.1 \pm 33.1$ \\
\hline Postprandial & $175.8 \pm 69.3$ & $167.5 \pm 68.3$ & $156.8 \pm 47.2$ \\
\hline $\begin{array}{l}\text { HbA1c } \\
\text { Serum lipid parameters }\end{array}$ & $6.92 \pm 1.2$ & - & $6.73 \pm 1.2$ \\
\hline Total cholesterol (mg/dL) & $179.5 \pm 39.0$ & - & $163.8 \pm 32.2$ \\
\hline LDL-C ( mg/dL) & $105.8 \pm 30.0$ & - & $91.7 \pm 25.6$ \\
\hline HDL-C ( mg/dL) & $39.6 \pm 7.1$ & - & $39.5 \pm 7.4$ \\
\hline VLDL- C (mg/dL) & $30.5 \pm 12.1$ & - & $30.1 \pm 11.8$ \\
\hline Triglyceride (mg/dL) & $173.8 \pm 85.7$ & - & $154.2 \pm 60.4$ \\
\hline TC:HDL ratio & $4.6 \pm 0.8$ & - & $4.2 \pm 0.9$ \\
\hline TG:HDL ratio & $4.6 \pm 2.5$ & - & $4.1 \pm 1.9$ \\
\hline Blood pressure & $81.1 \pm 3.8$ & $80.4 \pm 2.9$ & $80.7 \pm 3.3$ \\
\hline $\begin{array}{l}\text { Systolic blood pressure } \\
\text { (mm Hg) }\end{array}$ & $128.9 \pm 8.8$ & $127.2 \pm 9.3$ & $127.6 \pm 7.1$ \\
\hline $\begin{array}{l}\text { Diastolic blood pressure } \\
\text { (mm Hg) }\end{array}$ & & & \\
\hline
\end{tabular}

Table 9: Group III at different periods of evaluation.

study as compared to the beginning of the study in Group II subjects. No significant differences were noted in HDL, VLDL levels and TC:HDL ratio at the end of the study as compared to the beginning of the study. Serum triglyceride levels and TG:HDL ratio showed a nonsignificant increase at the end of 180 days as compared to the beginning of the study. Systolic and diastolic blood pressure levels showed a nonsignificant increase after 90 days and a non-significant decrease after 180 days as compared to the beginning of the study.

The mean values of the anthropometric measurements, plasma glucose parameters, $\mathrm{HbA1c}$, serum lipid parameters and blood pressure levels of the subjects in Group III at different periods of evaluation are given in Table 9 below.
In Group III subjects, there was a statistically significant $(\mathrm{p}<0.05)$ decrease in both the body weight and the BMI at the end of 90 days and a non- significant decrease at the end of 180 days as compared to the beginning of the study. Fasting plasma glucose levels showed a statistically significant $(\mathrm{p}<0.05)$ decrease at the end of both 90 and 180 days as compared to the beginning of the study. There was a decrease in the postprandial glucose levels at the end of 90 days and a statistically significant $(\mathrm{p}<0.05)$ decrease at the end of 180 days.

There was a non-significant decrease in glycosylated hemoglobin levels at the end of 180 days. There was a statistically significant $(\mathrm{p}<0.05)$ reduction in serum total cholesterol and LDL cholesterol levels at the end of 180 days as compared to the beginning of the study in Group III subjects. There was no significant change in the serum HDL cholesterol and VLDL levels. Serum triglyceride level showed a non-significant decrease at the end of 180 days of the study.

There was a statistically significant $(p<0.05)$ decrease in TC: HDL ratio at the end of 180 days. A non-significant decrease in TG:HDL ratio was noticed at the end of 180 days. Systolic and diastolic blood pressure levels showed a non-significant decrease at the end of both 90 and 180 days as compared to the beginning of the study.

There was no significant correlation noticed between the body mass index and serum total cholesterol levels of the subjects in all the three groups at different periods of evaluation. Subjects of Groups II and III did not show any significant correlation between body weight and fasting plasma glucose levels at different periods of evaluation. Subjects of Group I showed a statistically significant correlation $(p<0.05)$ between mean body weight and fasting plasma glucose levels at day one and at the end of 180 days of the study. No significant correlation was found between mean body weight and postprandial plasma glucose levels in the subjects of all the three groups at different periods of evaluation.

The present study was conducted on subjects with type 2 diabetes mellitus to assess the risk factors related to the complications of the disease. There was a general trend noticed towards a reduction in BMI, plasma glucose levels, serum lipid parameters and blood pressure levels that are the indicators of development of complications such as cardiac disease and nephrological complications. Subjects of Group II and Group III have shown a statistically significant reduction in the BMI. Reduction in body weight and BMI are essential for good glycemic control and reduction in risk factors for CVD, a trend to be followed by subjects with type 2 diabetes mellitus. The periodical intensive counselling on diet and counselling on diet and exercise has helped in managing the body weight and BMI of these subjects. Reduction in body weight and BMI will help in the overall control of the condition.

\section{Role of Researchers}

Dr Dharini Krishnan designed and collected data for the study. Dr Abdul Hafeez-Baig and Professor Nilmini Wickramasinghe helped with data analyses. Professors Raj Gururajan and Srinivas KondalasamyChennakesav helped with data organisation, paper organisation and data validation. Miss Rashmi Gururajan helped the team in compiling this paper.

\section{Acknowledgement}

The team acknowledges Mrs Vasundhara Rani in helping us with compiling reference lists, editing references and proofing the article. We acknowledge $\mathrm{Dr}$ Gomathi for supervision and guidance provided.

Guarantor's statement should read as follows: Professor Raj Gururajan is the guarantor of this work and, as such, had full access to all the data in the study 
Citation: Krishnan D, Gururajan R, Baig AH, Chennakesavan SK, Wickramasinghe N, et al. (2015) The Impact of Diet Counselling on Type 2 Diabetes Mellitus: An Indian Case Study. J Diabetes Metab 6: 610. doi:10.4172/2155-6156.1000610

and takes responsibility for the integrity of the data and the accuracy of the data analysis.

We confirm that there is no conflict of interest for any author as a result of this study.

\section{References}

1. Webster (2003) New World Medical Dictionary (2nd edtn) John Wiley and Sons, USA.

2. Webb GP (2002) Nutrition: A health promotion approach (2nd edtn) Arnold Publishers, USA

3. Ramachandran A (2002) Urban India a Breeding ground for Diabetes. Diabetes Voice 47: 18-20.

4. Mohan V, Sandeep S, Deepa R, Shah B, Varghese C (2007) Epidemiology of type 2 diabetes: Indian scenario. Indian J Med Res 125: 217-230.

5. Diabetes Atlas (2003) Executive Summary. (2nd edtn) International Diabetes Federation.

6. Wild S, Roglic G, Green A, Sicree R, King H (2004) Global prevalence of diabetes: estimates for the year 2000 and projections for 2030. Diabetes Care 27: 1047-1053.

7. Saleh F, Mumu SJ, Ara F, Hafez MA, Ali L (2014) Non-adherence to self-care practices \& medication and health related quality of life among patients with type 2 diabetes: a cross-sectional study. BMC Public Health 14: 431.

8. Mohan V, Shanthirani S, Deepa R, Premalatha G, Sastry NG, et al. (2001) Intra-urban differences in the prevalence of the metabolic syndrome in southern India -- the Chennai Urban Population Study (CUPS No. 4). Diabet Med 18: 280-287.

9. Ramachandran A, Snehalatha C, Vijay V (2004) Low risk threshold for acquired diabetogenic factors in Asian Indians. Diabetes Res Clin Pract 65: 189-195.

10. Ramachandran A, Snehalatha C, Latha E, Vijay V, Viswanathan M (1997) Rising prevalence of NIDDM in an urban population in India. Diabetologia 40: 232-237.

11. Ramachandran A (2005) Epidemiology of diabetes in India--three decades of research. J Assoc Physicians India 53: 34-38.

12. Mohan V, Deepa M, Deepa R, Shanthirani CS, Farooq S, et al. (2006) Secular trends in the prevalence of diabetes and impaired glucose tolerance in urban South India - the Chennai Urban Rural Epidemiology Study (CURES-17). Diabetologia 49: 1175-1178.

13. Singh RB, Bajaj S, Niaz MA, Rastogi SS, Moshiri M (1998) Prevalence of type 2 diabetes mellitus and risk of hypertension and coronary artery disease in rural and urban population with low rates of obesity. Int J Cardiol 66: 65-72.

14. Yajnik CS (2004) Early life origins of insulin resistance and type 2 diabetes in India and other Asian countries. J Nutr 134: 205-210.

15. Ramachandran A (2003) Successful multiple risk factor intervention in Type 2 diabetes. DiabetesVoice 48, 44-46.

16. Harvey JN, Craney L, Kelly D (2002) Estimation of the prevalence of diagnosed diabetes from primary care and secondary care source data: comparison of record linkage with capture-recapture analysis. J Epidemiol Community Health 56: $18-23$.

17. Gupta OP, Sanjeev P (2003) Pandemic Trends in Prevalence of Diabetes Mellitus and Associated Coronary Heart Disease in India - Their Causes and Prevention. International Journal of Diabetes in the Developing Countries 23 : $37-50$

18. Hadaegh F, Bozorgmanesh MR, Ghasemi A, Harati H, Saadat N, et al. (2008) High prevalence of undiagnosed diabetes and abnormal glucose tolerance in the Iranian urban population: Tehran Lipid and Glucose Study. BMC Public Health 8: 176 .

19. Abate N, Chandalia M (2001) Ethnicity and type 2 diabetes: focus on Asian Indians. J Diabetes Complications 15: 320-327.

20. Jali MV, Kambar S (2006) Prevalence of diabetes amongst the family members of known diabetics. International Journal of Diabetes in the developing countries 26: 81-85.

21. Davidson SS, Passmore R, Eastwood MA (1986) Human Nutrition and Dietetics (8th edtn), English Language Book Society, Great Britain.
22. American Diabetes Association, Bantle JP, Wylie-Rosett J, Albright AL, Apovian CM, et al. (2008) Nutrition recommendations and interventions for diabetes: a position statement of the American Diabetes Association. Diabetes Care 31 Suppl 1: S61-78.

23. American Diabetes Association (2002) Standards of medical care for subjects with diabetes mellitus. Diabetes Care 25: S33-S49.

24. Seshiah V (1989) Diabetes Mellitus, Jaypee Brothers, New Delhi.

25. Kohnert KD, Augstein P, Zander E, Heinke P, Peterson K, et al. (2009) Glycemic variability correlates strongly with postprandial beta-cell dysfunction in a segment of type 2 diabetic patients using oral hypoglycemic agents. Diabetes Care 32: 1058-1062.

26. Feinglos MN, Bethel MA (2008) Type 2 Diabetes Mellitus An Evidence- Based Approach to Practical Management, Springer Verlag, Germany.

27. Shah SK, Saikia M, Snehalatha C, Ramachandran A (1999) High prevalence of Type 2 Diabetes in north eastern India. Int j diab dev countries 19: 144-147.

28. Mudaliar S, Henry RR (1999) Combination therapy for type 2 diabetes. Endocr Pract 5: 208-219.

29. Desai A, Tandon N (2007) Management of type 2 diabetes mellitus with oral antihyperglycaemic therapy. Natl Med J India 20: 192-198.

30. Chehade JM, Mooradian AD (2000) A rational approach to drug therapy of type 2 diabetes mellitus. Drugs 60: 95-113.

31. Okamoto T, Okamoto L, Lisanti MP, Akishita M (2008) Switch to oral hypoglycemic agent therapy from insulin injection in patients with type 2 diabetes. Geriatr Gerontol Int 8: 218-226.

32. Sridhar GR, Madhu K (2001) Stress in the Cause and Course of Diabetes International Journal of Diabetes in developing countries 21: 112-120.

33. Holleman F, Hoekstra JBL (1997) Insulin Lispro. N Engl J Med 337: 176-183.

34. Østoft SH, Christensen M (2015) An alternative combination therapy for type 2 diabetes? Lancet 385: 2020-2022.

35. Genuth S (1996) Exogenous insulin administration and cardiovascular risk in non-insulin-dependent and insulin-dependent diabetes mellitus. Ann Intern Med 124: 104-109.

36. Franz MJ, Bantle JP, Beebe CA, Brunzell JD, Chiasson JL, et al. (2002) Evidence-Based Nutrition Principles and Recommendations for the Treatment And Prevention of Diabetes and Related Complications. Diabetes Care 25 148-198.

37. Brink SJ (2014) Cum ar trebui tratati copiii si adolescentii cu diabet zahara tip 2? (romanian), How Should Children And Youth With Type 2 Diabetes Be Treated? (English) 17: 28-32

38. Ahuja MMS (1983) Practice of Diabetes Mellitus, Vikhas Publishing House Pvt. Ltd., New Delhi.

39. Albright A, Franz M, Hornsby G, Kriska A, Marrero D, et al. (2000) American College of Sports Medicine position stand. Exercise and type 2 diabetes. Med Sci Sports Exerc 32: 1345-1360.

40. Krall LP, Beaser RS (1989) Joslin's Diabetic Manual , 12th Edition, Lea and Febiger, Philadelphia.

41. Halpern SL (1987) Quick Reference to Clinical Nutrition: A guide for Physicians (2nd edtn) J.B. Lipincott Company, Philadelphia.

42. Boon How C, Mastura I, Shariff-Ghazali S, Ping Yein L, Ai Theng C, et al. (2012) Determinants of uncontrolled hypertension in adult type 2 diabetes mellitus: an analysis of the Malaysian diabetes registry 2009. Cardiovascular Diabetology 11:54-61.

43. Cheng Y, Zhang H, Chen R, Yang F, Li W, et al. (2014) Cardiometabolic risk profiles associated with chronic complications in overweight and obese type 2 diabetes patients in South China. PLoS One 9: e101289.

44. Chew BH, Ismail M, Lee PY, Taher SW, Haniff J, et al. (2012) Determinants of uncontrolled dyslipidaemia among adult type 2 diabetes in Malaysia: The Malaysian Diabetes Registry 2009. Diabetes Research \& Clinical Practice 96: 339-47.

45. Purohit $P$ (2014) A correlation study of CVD risk factors in Type 2 diabetics of Western Rajasthan. International Journal of Diabetes in Developing Countries 34: 215-219. 
Citation: Krishnan D, Gururajan R, Baig AH, Chennakesavan SK, Wickramasinghe N, et al. (2015) The Impact of Diet Counselling on Type 2 Diabetes Mellitus: An Indian Case Study. J Diabetes Metab 6: 610. doi:10.4172/2155-6156.1000610

46. Renzaho A, Bilal P, Marks, G (2014) Obesity, Type 2 Diabetes and High Blood Pressure Amongst Recently Arrived Sudanese Refugees in Queensland, Australia. Journal of Immigrant \& Minority Health, 16: 86-94

47. de Alba Garcia JG, Rocha AL, Lopez I, Baer RD, Dressler W, et al. (2007) "Diabetes is my companion": lifestyle and self-management among good and poor control Mexican diabetic patients. Soc Sci Med 64: 2223-2235.

48. Safari M, Yazdanpanah B, Yazdanpanah B, Mobasheri A (2014) A populationbased screening of type 2 diabetes in high-risk population of Yasuj, Iran. J Health Popul Nutr 32: 677-686.

49. Yardley JE, MacMillan F, Hay J, Wittmeier K, Wicklow B, et al. (2015) The Blood Pressure Response to Exercise in Youth with Impaired Glucose Tolerance and Type 2 Diabetes. Pediatric Exercise Science 27: 120-127.

50. Boyd AE, Huynh TG (1990) Sulphonylurea and antihypertensive drugs for type II diabetics. Contem. Intern Med 2: 13-33.

51. Helmrich SP, Ragland DR, Leung RW, Paffenbarger RS Jr (1991) Physical activity and reduced occurrence of non-insulin-dependent diabetes mellitus. $\mathrm{N}$ Engl J Med 325: 147-152.

52. Schneider SH, Khachadurian AK, Amorosa LF, Clemow L, Ruderman NB (1992) Ten-year experience with an exercise-based outpatient life-style modification program in the treatment of diabetes mellitus. Diabetes Care 15: 1800-1810.

53. Manson JE, Nathan DM, Krolewski AS, Stampfer MJ, Willett WC, et al. (1992) A prospective study of exercise and incidence of diabetes among US male physicians. JAMA 268: 63-67.

54. Hu FB, Sigal RJ, Rich-Edwards JW, Colditz GA, Solomon CG, et al. (1999) Walking compared with vigorous physical activity and risk of type 2 diabetes in women: a prospective study. JAMA 282: 1433-1439.

55. Hu FB, Manson JE, Stampfer MJ, Colditz G, Liu S, et al. (2001) Diet, lifestyle, and the risk of type 2 diabetes mellitus in women. N Engl J Med 345: 790-797.
56. Friedewald WT, Levy RI, Fredrickson DS (1972) Estimation of the concentration of low-density lipoprotein cholesterol in plasma, without use of the preparative ultracentrifuge. Clin Chem 18: 499-502.

57. Kalra S (2014) Alpha glucosidase inhibitors. J Pak Med Assoc 64: 474-476.

58. Will JC, Galuska DA, Ford ES, Mokdad A, Calle EE (2001) Cigarette smoking and diabetes mellitus: evidence of a positive association from a large prospective cohort study. International Journal of Epidemiology 30: 540-546.

59. American Diabetes Association (2008) Diagnosis and Classification of Diabetes Mellitus. Diabetes Care 31: S55-S60.

60. Morton DJ, Garrett M, Reid J, Wingard DL (2008) Current smoking and type 2 diabetes among patients in selected Indian Health Service clinics, 1998-2003. Am J Public Health 98: 560-565.

61. Engelgau MM, Narayan KM, Saaddine JB, Vinicor F (2003) Addressing the burden of diabetes in the 21st century: better care and primary prevention. Am Soc Nephrol 14: S88-91.

62. Holbrook TL, Barrett-Connor E, Wingard DL (1990) A prospective populationbased study of alcohol use and non-insulin-dependent diabetes mellitus. Am J Epidemiol 132: 902-909.

63. Tsumara K, Hayashi T, Suematsu C, Endo G, Fujii S, et al. (1999) Daily alcoho consumption and the risk of type 2 diabetes in Japanese men, the Osaka Health Survey. Diabetes Care 22, 1432-1437.

64. Carlsson S, Hammar N, Grill V, Kaprio J (2003) Alcohol consumption and the incidence of type 2 diabetes: a 20-year follow-up of the Finnish twin cohort study. Diabetes Care 26: 2785-2790.

65. Brekke HK, Lenner RA, Taskinen MR, Månsson JE, Funahashi T, et al (2005) Lifestyle modification improves risk factors in type 2 diabetes relatives. Diabetes Res Clin Pract 68: 18-28. 